\title{
GAME BASE LEARNING IN PSYCHOLOGY EDUCATION: IMPROVING UNDERGRADUATES COMPETENCE FOR TEAM WORKING
}

\author{
P. Martín-Hernández ${ }^{1}$, J.L. Azkue ${ }^{2}$, S. Agut ${ }^{3}$ \\ ${ }^{1}$ Facultad de Ciencias Sociales y Humanas, Universidad de Zaragoza (SPAIN) \\ ${ }^{2}$ Facultad de Ciencias de la Salud, Universidad de Zaragoza (SPAIN) \\ ${ }^{3}$ Facultad de Ciencias de la Salud, Universitat Jaume I (SPAIN)
}

\begin{abstract}
Gamification has been identified, as an interesting tool, to make educational processes more efficient. It supposes the application of gameful thinking, and game mechanics, in non-game contexts to engage users in solving problems or carrying out tasks. There is solid and growing empirical evidence that supports how games can favour effective learning in a variety of subjects. Some findings showed, that the mean scores of university students in classrooms using the game were significantly higher than those in classes that did not, supporting the idea that knowledge acquisition and content understanding can be learning from games. Moreover, it has been found that simulation games build more confidence for on-the-job application of learned knowledge, than classroom instruction does. Throughout their university training. Psychology undergraduates must acquire various knowledges and competences that are necessary to exercise their future professional activity in an effective and efficient way. Among them is the competence to work in teams, as well as to manage teams and groups so that they work properly. An important part of key knowledges to develop such competences are worked and developed in the classroom of Groups Psychology, at the end of the third course of Psychology Degree.

In this context this paper deals, on one hand, with the development of a proposal of a game-based learning experience amongst Psychology undergraduates and on the other hand, with testing its effects on such undergraduates' own competence perceptions for teamworking. We developed a simulation game called "the group to the rescue" that implies for the undergraduates to be confronted as a group to a new and a potential stressing situation that needs a fast and effective solution. In order to identify that solution, it is necessary to use some of the learnings and knowledges related to the physical and social environment of the groups that will be easier acquired and interiorized through this game. Moreover, this simulation game will have a positive impact in terms of building more confidence in one's own competence perception for teamwork. Our results, in a sample composed by the 31 Psychology Undergraduates that participated in the game, showed that after it, undergraduates have a higher perception of their competence for working effectively in teams. These findings are useful in order to foster the development of team working competence.
\end{abstract}

Keywords: Game-based learning, Groups Psychology, team working competence.

\section{INTRODUCTION}

Gamification, supposes the application of gameful thinking and game mechanics in non-game contexts to engage users in solving problems or carrying out tasks [1]. It can adopt a wide variety of forms (e.g. the use of narratives in order to change the context around a typical activity, the creation of social competition, and the incentivizing of behavior through reward systems), so it is considered by scholars as an interesting tool to make educational processes more efficient, and also contributes to transform higher education [2]. Serious games, gamification and game-based learning are designed for the primary target of educating or training, often combining the needed concentration by challenging activities and the enjoyment experienced when maximally utilizing one's skills [3]. There is solid and growing, but still limited [2], empirical evidence that supports how games can favour effective learning in a variety of subjects [4]. Some findings, reveal that the mean scores of university students in classrooms using the game were significantly higher than those in classes that did not, supporting the idea that knowledge acquisition and content understanding can be learning from games [5] in an enjoying, motivating and engagement way. Moreover, gamification could represent a more efficient teaching and learning strategy than other tools, such as lectures, so that the competences acquired during the training process are transferred more successfully to the work context [5]. In fact, simulation 
games build more confidence for on-the-job application of learned knowledge than classroom instruction does [6][7]. Even, there is not one universal definition for simulation, most of them emphasize that constitutes an imitation of a system involving the construction of an artificial history, with the real system features [8]. Simulation games simultaneously engage trainees' cognitive and affective processes [9] leading to higher levels of declarative and procedural knowledge as well retention for trainees taught, especially if such simulation games convey course material actively rather than passively [6]. The choice of a certain type of simulation depends on several factors, such as, for example, the training needs and the available resources. Low cost technologies [10], such as case studies and role plays, are effective to train teamwork related knowledge, skills, and attitudes in several contexts.

Throughout their university training, Psychology undergraduates must acquire different conceptual competences, required to exercise their future professional activity in an effective and efficient way. One of those competences deals with working in teams, as well as, the ability to manage teams and groups, so that they work properly. These competences must be developed in the subject of Groups Psychology, at the end of the third course of the Degree in Psychology. The list of important topics to learn and work in this subject is extensive, but among all of them the so-called effects of the physical, social and personal environment on group dynamics and performance are especially relevant. Some potential characteristics of special and exotics environments, where group sometimes must work (e. $\mathrm{g}$. hostile physical climate, danger) influence interaction group patterns, as well as they test the physical, psychological and social abilities of the members of the group [11]. Group size, which involves the most visible structural factor of the group, delimits the group context, exerting a critical influence also on different variables and group processes. Previous research suggests that the optimal size of small groups ranges from 4 to 12 members, depending on the type of task that the group have to perform. In the case of those groups whose tasks consist of solving problems and/or making decisions, the optimal size seems to be 5 members. Finally, some sociodemographic, personality, attitudinal, and intellectual characteristics of group members configure an idiosyncratic composition, influencing group interaction, dynamics, and performance. In the case of age, the empirical evidence reveals that as the chronological age, increased the interaction with others becomes more selective and complex. Women tend to use more nonverbal communication and to adopt a more democratic leadership style, than their male counterparts. People with a positive orientation towards other group members promote social interaction, cohesion and morality in groups, while those who exhibit unconventional behaviour tend to inhibit the effective functioning of the group [11].

In this study, we developed a proposal of a game-based learning experience amongst Psychology undergraduates, where we tested how this experience could impact positively on their perception, on their team working competence. We designed a simulation game called "the group to the rescue" where the undergraduates, as a group, had to cope with a new and a potential stressing situation that needed a fast and effective solution. In order to identify such solution, they had to use some competences related to the aforementioned physical, social and personal environment effects over the groups. In addition, we expected this simulation game would have a positive impact in terms of building more confidence in their own competence perception for working in teams.

\section{METHODOLOGY}

\subsection{Participants}

A total of 31 Psychology undergraduate students participated in the game (48\% of the total of those enrolled in the subject Group Psychology). They were randomly assigned to this game condition, on the basis of alphabetical order by last name. Before and after the game participants completed the instrument used to measure the researched variables. Written consent was obtained as a previous step. Participants' age ranged from 20 to 24 years old $(M=20.7 ; S D=.88)$. Of them, $87.1 \%$ were women.

\subsection{Measures}

Confidence in own competence perception for working in teams was assessed using a 21 items instrument that captures students perceptions regard to their own teamwork behaviours associated with team member effectiveness [12][13]. A sample item is "I assist my teammates when needed". Items were ranged on a 6-point Likert scale from 1 (completely disagree) to 6 (completely agree). Cronbach's $\alpha$ were 0.83 before playing the game (T1) and 0.91 after played it (T2). 


\subsection{Procedure}

Firstly, we designed and wrote the game that the different teams had to play. Six teams were composed of around five members. These teams had a maximum of 45 minutes to complete the game. Before and after playing the game, participants completed the instrument we used to measure the variables.

\section{RESULTS}

\subsection{The game "the group to the rescue"}

Here the so-called effects of the physical, social and personal environment on group dynamics and performance are especially relevant. First of all, we listed the exact contents that could be worked and learned by playing.

On the one hand, we included some potential characteristics of special and exotics environments where group sometimes must work. The scenario consisted of travelling through space in a small spaceship for two month round trip, along with an indeterminate stay in a newly discovered planet, with an atmosphere such as terrestrial but with a very cold climate, large animals (including dinosaurs), and an exotic vegetation. So we create, Tesaltion, a planet suitable for Humans life, recently discovered although this still almost nobody knows, as well as the Chachigate I, a last generation spaceship, very fast, barely 50 square meters.

On the other hand, we selected those research results related to the optimal group size (around five for those groups whose tasks consist of solving problems and/or making decisions), as well as, to some sociodemographic, personality characteristics, attitudinal and intellectual characteristics of group members, which configure an idiosyncratic composition, influencing group interaction, dynamics and performance. We created twelve different characters that varied in age, gender, ethnicity, abilities, personality traits, intelligence and attitudes. An example of two of such characters can be described as follows: "S. ROMEZ, when she was 25 years old, became the youngest lieutenant in the army of her country, and left for a detachment in a highly conflictive zone in the middle of the jungle. Now, she is 45 years old. Her specialty: Tracking, she is able to "smell" the danger miles away. Neither motherhood - has got three children-, nor the passage of time, has made her, lose her faculties. Highly valued by his subordinates, believes in democracy". "M. PITTON: 68 years old, retired military man with the spirit of a Renaissance man, the list of his skills and knowledge is long: biology, astrophysics, linguistics, palaeontology, architecture, geology, telecommunications ... He receives the nickname "Sabelotodo". He inspires confidence and takes anxiolytics."

Then, we created a narrative imitation of a system involving the construction of an artificial history, with the real system features convey course material actively. This narrative starts telling pupils that "the Earth shrinks". Researchers from the Teruel Campus have discovered that every second that passes, one millionth of a centimetre of the earth disappears. At the same time, Scientists from the astronomical observatory of Teruel have discovered a new planet almost around the corner of the Earth, which they have baptized as TESALTIÓN. Someone very, very important person and his team of advisers are convinced that life in Tesaltión is possible, and its proximity to the Earth will facilitate the evacuation work. But before that, it becomes necessary to confirm in situ, if what apparently seems to be able to save humanity, can really do so. For doing this, they plan to send an exploration and recognition team. And it is here, where that important individual requires your expertise: he knows that you are specialists in Group Psychology. The task consists of forming a group whose mission is travelling to Tesaltión, successfully. They should explore it, and indicate, on the basis of the information they gather, if it is possible to live in; also whether that place was appropriate to the survival of the humanity, or whether, on the contrary, the searching of an alternative planet is a better option. This team will have to explore and surely make decisions. They will have to travel through space for two months - round trip - in the Chachigate I, which although it is very fast and does not need a pilot, is not bigger than the room in which you are now. They will have to spend on Tesaltion, as long as necessary, and that, right now it is not possible to determine. Of course, they have some candidates for the mission, but they do not know for sure how many of them the group should be composed of, or who are the best".

Finally, we gave every team a report called "the classified report TOP-SECRET" with the characteristics of every character. We said them "please form that group, and provide that someone so important with the reasons for your choice, THE WORLD NEEDS YOU!!!! You have 45 minutes to 
complete every team report, and for doing so, in return, neither you, nor your families, nor your loved ones and friends will suffer any damage: You will have a preferred place in the ship CHACHIGATE II, when it is built. The first group that completed the report will have a V.I.P. place in the spaceship". Every group had to provide a report signing all the elected members to conform the group that will explore Tesaltion in the order in which she or he was incorporated to the group, explaining the main reasons taken into account to shape such group.

\subsection{T-test analysis and results}

Significant differences between the mean scores in T1 (before playing the game) and time T2 (after playing the game) in terms of confidence in the own competence perception for working in teams were obtained. As can be seen in Table 1 the follow-up paired t-test indicated that playing the game produced an enhancement of the self-perceived competence for working in teams $(t(30)=-2.771 ; p<$ $.01)$, being higher in time 2 (MeanT1= 4.96, MeanT2= 5.13).

Table 1. T-test: Confidence on own competence for teamworking.

\begin{tabular}{l|c|c|c|c|c|c|c}
\hline \hline & Time & $\mathrm{N}$ & Mean & SD & \multicolumn{3}{|c}{ T-test } \\
\hline & 1 & 31 & 4.96 & 0.35 & -2.771 & 30 & $0.009^{* *}$ \\
$\begin{array}{l}\text { Competence } \\
\text { perception for working } \\
\text { in teams }\end{array}$ & 2 & 31 & 5.13 & 0.49 & & & \\
\hline \hline$* * 01$
\end{tabular}

\section{CONCLUSIONS}

This paper dealt, on one hand, with the development of a proposal of a game-based learning experience amongst Psychology undergraduates, and on the other hand, with testing its effects on the undergraduates' perceived competence for teamworking. Firstly, we developed a simulation game called "the group to the rescue" that implied for the undergraduates to be confronted, as a group, to a new and a potential stressing situation that needed a fast and effective solution. In order, to identify such solution, it was necessary to use some of the learnings and knowledges related to the physical and social environment of the groups, which would be acquired and interiorized through this game in an easier way. Moreover, this simulation game had a positive impact in terms of building more confidence in their own competence perception, for working in teams. Our results showed that after playing this game, undergraduates have a better perception of their own competence for working in teams effectively. In order words, the game functioned in terms of training related knowledge and competences in the context of Group Psychology [10]. These findings are useful in order to foster the development of team working competence, and could be also added to previous, but limited evidence [2], in supporting the usefulness of gamification [14].

This study is not exempt from limitations. The study has a higher number of female participants than male participants. However, no significant differences appear in previous research regard to the relationship between gender and game based-learning. A potential explanation could be that in game based learning tasks female and male agree on the need for teamwork and all of them will adopt a cooperative orientation [15]. In any case, future studies including higher number of male participants could be developed, and so shed light on the conditions under which variables, such as, gender composition of the group, could condition game effectiveness in terms of enhancing confidence, in one's own competence, for teamworking.

In conclusion, the findings highlight the potential of tasks that involve gaming to contribute to the enhancement of core competencies, such as teamwork, that are essential as future professionals. The influence of games, on teaching and learning process will need to be approached from distinct domains (i.e., instruction, pedagogy, and assessment). In addition, educational policies friendly and open to games as a potentially effective educational offering, are still required [3]. 


\section{ACKNOWLEDGEMENTS}

This study had been possible thanks to the teaching innovation project "La gamificación como herramienta de fomento del aprendizaje activo y la construcción de equipo (Team Building)" PIIDUZ_17_159, Vicerrectorado de Política Académica, Universidad de Zaragoza. We also want to express our gratitude to the Department of Psychology and Sociology of the University of Zaragoza and to all the participants in this study.

\section{REFERENCES}

[1] S. Deterding, M. Sicart, L. Nacke, K. O'Hara, \& D., Dixon, "Gamification: using game-design elements in non-gaming contexts", in Proceedings of the 2011 Annual Conference on Human Factors in Computing Systems, pp. 2425-2428, 2011.

[2] M. D. Hanus, \& J. Fox, "Assessing the effects of gamification in the classroom: A longitudinal study on intrinsic motivation, social comparison, satisfaction, effort, and academic performance", Computers \& Education, vol. 80, pp. 152-160, 2015.

[3] J. Hamari, D. J. Shernoff, E. Rowe, B. Coller, J. Asbell-Clarke, \& T. Edwards, "Challenging games help students learn: An empirical study on engagement, flow and immersion in gamebased learning", Computers in Human Behavior, vol. 54, January, pp. 170-179, 2016.

[4] D., Dicheva, C. Dichev, G. Agre, \& G. Angelova, "Gamification in education: A systematic mapping study", Journal of Educational Technology \& Society, vol. 18, no. 3, pp. 75-88, 2015.

[5] K. KAPP, "Once Again, Games Can and Do Teach!", 2013. Retrieved from https://www.learningsolutionsmag.com/articles/1113/once-again-games-can-and-do-teach.

[6] T. Sitzmann, "A meta-analytic examination of the instructional effectiveness of computer-based simulation games", Personnel Psychology, vol. 64, no 2, pp. 489-528, 2011.

[7] M. Sailer, J. Hense, H. Mandl, \& M. Klevers, "Fostering development of work competencies and motivation via gamification" in Competence-based Vocational and Professional Education (M. Mulder ed.), pp. 795-818. Cham: Springer, 2017.

[8] P. S. Silva, A. Trigo, J. Varajão, \& T. Pinto, "Simulation-concepts and applications", in World Summit on Knowledge Society (M. D. Lytras et al. eds.), pp. 429-434, Berlin, Heidelberg: Springer, 2010.

[9] R. D, Tennyson, \& R.L. Jorczak, "A conceptual framework for the empirical study of instructional games" in Computer games and team and individual learning (H. F. O'Neil \& R. S. Perez eds.), pp. 39-54, Oxford, UK: Elsevier, 2008.

[10] J. M. Beaubien, \& D. P. Baker, "The use of simulation for training teamwork skills in health care: how low can you go?", BMJ Quality \& Safety, vol. 13, suppl. 1, pp. i51-i56, 2004.

[11] F. Gil \& C. M. Alcover, Introducción a la Psicología de los Grupos. Madrid: Pirámide, 2008.

[12] M. B. Donia, T. A. O'Neill, \& S. Brutus, "The longitudinal effects of peer feedback in the development and transfer of student teamwork skills". Learning and Individual Differences, vol. 61, pp. 87-98, 2018.

[13] S. Brutus, \& M. B. Donia, "Improving the effectiveness of students in groups with a centralized peer evaluation system", Academy of Management Learning \& Education, vol. 9, no. 4, pp. 652-662, 2010.

[14] J. Hamari, J. Koivisto, \& H. Sarsa, "Does gamification work?- A literature review of empirical studies on gamification", in proceedings of the 47th Hawaii International Conference on System Sciences (HICSS), pp. 3025-3034. Hawaii, USA, January 6-9, 2014

[15] C. K. De Dreu, "Cooperative outcome interdependence, task reflexivity, and team effectiveness: A motivated information processing perspective", Journal of Applied Psychology, vol. 92, no. 3, pp. 628-638, 2007. 